\title{
Knowledge Management in Virtual Communities of Practice
}

\author{
Júnio César de Limaㄹ, Cedric Luiz de Carvalho² \\ and Ana Paula Laboissière Ambrósio² \\ ${ }^{1}$ Instituto Federal Goiano - Campus Urutaí \\ 2 Instituto de Informática - Universidade Federal de Goiás \\ Brazil
}

\section{Introduction}

Virtual Communities of Practice (VCoPs) are groups of people who get together to discuss and share their knowledge on a given domain using a virtual environment. Experiences are exchanged within the community. Members use community knowledge to solve their own problems and share the solution with the community. Thus, the more the community helps its members, the more its knowledge grows, and the more it becomes attractive to new members. Key to the concept of VCoPs is the management of knowledge acquired or developed by the community, which must be indexed and stored as to be easily retrieved. This is not an easy task since knowledge is stored in people's mind. It is therefore difficult to capture, to represent and to make persistent so other people can use.

The creation of VCoPs is well aligned with a strong tendency of the modern world, which presents a shift from an industrial society paradigm to that of a knowledge society. In this type of society, where knowledge is the sole really meaningful resource, it is important to have spaces for the representation and sharing of information that reflect the thought of professionals, researchers, teachers, students, etc..

On the other hand, the was designed to support resource sharing at a global level. It has, however, many limitations. The Semantic Web appears as a possible solution for some of these limitations. It represents a revolution in information processing and, consequently, a revolution in the way knowledge is organized. The Semantic Web requires all available resources to have enough expressiveness so machines and/or software agents are able to "understand" the real meaning of data. The use of these Semantic Web technologies can be very useful in the construction of tools to support VCoPs.

The central idea of this chapter is to structure the concepts of knowledge representation and retrieval, as well as to characterize how semantics can contribute in the management of knowledge within a virtual community of practice.

The first part of the chapter is an introduction to knowledge management. It describes some basic domain concepts, showing the relation between data, information and knowledge.

The second part, discusses Virtual Communities of Practice and the role of knowledge in this environment. Since the domain of a VCoP characterizes a shared interest, each member 
of the community is expected to have a minimum degree of domain knowledge. This common understanding can be used to the advantage of knowledge management. The use of ontology to represent the domain associated to Semantic Web technologies can contribute in the communication process, helping users to store, access and visualize information in a more transparent, democratic and intuitive way.

The third part of the chapter discusses how semantics can be used to help in the representation and retrieval of knowledge. Usually, when semantics is attributed to data or information, it facilitates their automatic processing. There are several tools that help in the retrieval of information in shared environments, but they still present problems, mainly linked to the lack of semantic treatment in documents and queries. This is due to imprecision and ambiguities inherent to the communication process. Meaning (semantics) is in the mind of people and not in graphic signs.

The fourth part discusses how the use of well-defined contexts may help reduce this problem. Ontology is being widely used to represent information context in shared environments, as they can be used to define domains, generating a set of words that identify it. Ontology therefore allows a common and shared comprehension of a domain, playing an important role in knowledge exchange by introducing a semantic structure for the data belonging to that domain.

The chapter concludes discussing in sections 5 the aspects that must be tackled by VCoP Environments to help manage the documents generated within the community, facilitating storage, indexation and retrieval. It discusses how these environments may contribute to the generation of new knowledge, encompassing the four modes of knowledge conversion represented in Nonaka and Takeuchi's spiral model, introducing Semantic Web Technologies. Section 6 concludes the chapter.

\section{Knowledge Management: an overview}

The term "Knowledge Management" appeared in the mid 90's and is the meeting point of the Information Technology and Administration domains. Landini and Damiani (2001) define knowledge management as a systematic process for connecting people to other people and to knowledge they need to act efficiently and create new knowledge. Its main objective is to enhance an enterprise's performance and that of its workers, not simply by sharing knowledge, even though this is a valuable sub product of the process, but through the identification, capture, validation and knowledge transference. Knowledge management has also been defined as a necessary process to capture, code and transfer knowledge so an enterprise can fully attain its objectives (Archer, 2006).

Initially, knowledge management was seen as an innovative manner of solving several organizational problems, creating what was referenced by Peter Druker (2006) as "Knowledge Society". The global importance of knowledge management has only recently been recognized, being treated as a critical resource for the success of enterprises.

However, knowledge management is still in its infancy. If, on one hand, technology and the development of information networks foster knowledge dissemination, on the other hand it facilitates direct publication by the author. This leads to a lack of patterns in the documents/information made available in the Internet, making search and retrieval more difficult. Thus, information technology is faced with the increasing challenge of offering this "new society" knowledge that is reliable, precise, on time and relevant. 
In addition to the lack of patterns, information processing to generate knowledge is, on its own right, a complex activity, since information, depending on the context and knowledge domain, may have several meanings. A term may represent different concepts with different conceptual relations depending on the situation.

Despite the evolution in the communication processes, enterprises have encountered difficulties in defining processes that minimize or solve the problems related to knowledge management, maintaining themselves competitive in face of the numerous innovation needs (Davenport \& Prusak, 1998). To fulfill this objective, it is necessary to create mechanisms and processes that facilitate knowledge manipulation. This implies understanding what is "knowledge", as well as the distinction between knowledge, information and data.

\subsection{Data}

According to Setzer (2006), data are mathematical entities and therefore purely syntactic. This means data can be fully described through formal structural representations. He suggests that information may be mentally characterized, but not physically defined, declaring that it is not possible to process information directly in a computer without it being reduced to data. Data processing in a computer is limited exclusively to their structural manipulation. He ends by arguing that knowledge is an internal, personal abstraction of something that was experienced by someone. In this argument, knowledge cannot be totally described, but may be conceptualized in terms of information.

Mizzaro (1997) arguments that, from a computational point of view, data is everything that is given as input to be processed, while information is everything that this process returns as output. Thus, there is no distinction, in computational processes, between data, information and knowledge, where all, assuming an input role, would be named data.

A more formal definition of data can be found in Davenport and Prusak (1998), where "Data are sets of distinct and objective facts related to an event". As proposed by Peter Drucker, cited in (Davenport \& Prusak, 1998), information is "data covered of small relevance". Thus it is necessary to aggregate value to this data so information can be obtained. This can be done through methods specified in Davenport and Prusak (1998):

- Contextualization: the purpose for which the data has been collected is known.

- Categorization: the data's essential analysis units or components are known.

- Calculus: data can be mathematically or statistically analyzed.

- Correction: errors are eliminated from the data.

- Condensation: data can be summarized into a more concise form.

\subsection{Information}

Information, according to Claude Shannon (2005), is "something that adds to a representation[...] We receive information when what we know is modified. Information is that which logically justifies the change or reinforcement of a representation or state of things. Representations may be explicit as in a map or proposition, or implicit as in the state of an activity oriented to the receptor".

In this approach, the concept of information is seen as something the receptor agent receives, through a message, from an emitting agent in a communication process. Its representation measure or importance is given by the Entropy, that defines the measure of importance of a word in the context of a given domain (Hotho et al., 2005). 
In opposition to Claude Shannon`s model, Dretske referenced in (Nonaka \& Takeuchi, 1995), arguments that a genuine information theory is a theory about message contents, and not a theory about the model in which this content is incorporated. Information is a flow of messages, while knowledge is created by that same message flow, anchored in the beliefs and commitments of its beholder. Thus knowledge is related to the human action (Nonaka \& Takeuchi, 1995).

According to Setzer (2006), information is an informal abstraction that is in the mind of a person, representing something meaningful to her, and cannot be formalized through a mathematical or logic theory. The information contained in a data depends on what a person knows about a theme and, in general, that can vary from person to person. Thus, what constitutes information for a person may not be more than data for others.

A fundamental distinction between data and information is that the first is purely syntactic and the second necessarily contains semantics. It is interesting to note that it is very hard to introduce and process semantics in a computer because the machine is purely syntactic (Setzer 2006). Today, there are several on going researches in this sense, being the Semantic Web (Berners-Lee et al., 2001) one of them. Its objective is to provide semantics to resources scattered in the web, making them processable by computers.

\subsection{Knowledge}

Knowledge is the object of Knowledge Management and Knowledge Engineering that aim to capture it, even though comprehension of its meaning is still controversial.

Knowledge, defined in Davenport and Prusak (1998), "is a fluid mixture of condensed experience, values, context information and experimental insight, that offers a structure for evaluation and incorporation of new experiences and information. It has an origin and is applied in the mind of experts. In organizations it is often embedded not only in documents and repositories, but also in routines, processes and organizational norms. "

Knowledge, in (Goble et. al., 2004), is described as information put into use to execute a goal or to fulfill an intention, being knowledge the result of the familiarity obtained by experience or association with some other knowledge.

According to Fischler and Firschein, referenced in (Haykin, 1998), knowledge refers to stored information or to models used by a person or machine to interpret, predict and respond appropriately to the exterior world. In a comparison between knowledge and data, knowledge is a complex symbolic representation of some aspect of the universe of discourse while data is a simple symbolic representation.

Knowledge can exist in two forms: tacit and explicit. "Explicit knowledge" is the knowledge that can be easily collected, organized and transferred through digital means while "tacit knowledge" is knowledge that is personal, in a specific context and hard to formalize and communicate.

Explicit knowledge is the knowledge that exists in documents, books, software and other means. Knowledge expressed in the explicit form may be easily reproduced and distributed at low cost, or no cost, but for that same reason is harder to guarantee its unauthorized use. Tacit knowledge is knowledge a person acquires during her life and is in her head. It may be the most valuable knowledge of a person or organization. Usually it is hard to be formalized and explained to another person, since it is highly localized, subjective and inherent to a person's abilities and requires, for its transfer, a direct involvement of the sources and users and an active teaching and learning process (Bolisani et. al., 2006). 
For Nonaka and Takeuchi (1995), knowledge is created through a cyclic process where tacit knowledge is converted into formalisms, symbols and becomes publicly available as explicit knowledge and vice-versa. To transform tacit knowledge into explicit knowledge, making it reusable by other people, is not an easy task. As described before, tacit knowledge is personal and hard to be articulated in a formal language as it involves several factors (emotional, psychological and others).

For knowledge transformation to occur, and thus its expansion, a social interaction is necessary between tacit and explicit knowledge. From there, the accumulated individual knowledge will need to be again socialized as to generate new concepts when applied to new needs. The conversion process from tacit into explicit and vice-versa may occur in four ways (Nonaka \& Takeuchi, 1995):

- Socialization: conversion from tacit to tacit. Is the experience sharing process between individuals in a group and usually occurs due to observation, imitation and practice. In this manner it is possible to transfer tacit knowledge between individuals and the association of a given type of knowledge to different individual contexts;

- Externalization: conversion from tacit into explicit. Is the organization process that transforms tacit knowledge into explicit knowledge through the use of metaphors, analogies, concepts, hypothesis and models, permitting the creation of new and explicit concepts based on the tacit knowledge;

- Combination: conversion from explicit into explicit. Is the concept systematization process in a knowledge system. It involves the combination of a set of explicit knowledge (such as classification, summarization, research and information categorization) using database technology and may lead to the creation of new knowledge;

- Internalization: conversion from explicit into tacit. Is the process through which explicit knowledge becomes a learning tool through the use of manuals and documents, and assumes again an abstract and subjective context for each member of the organization.

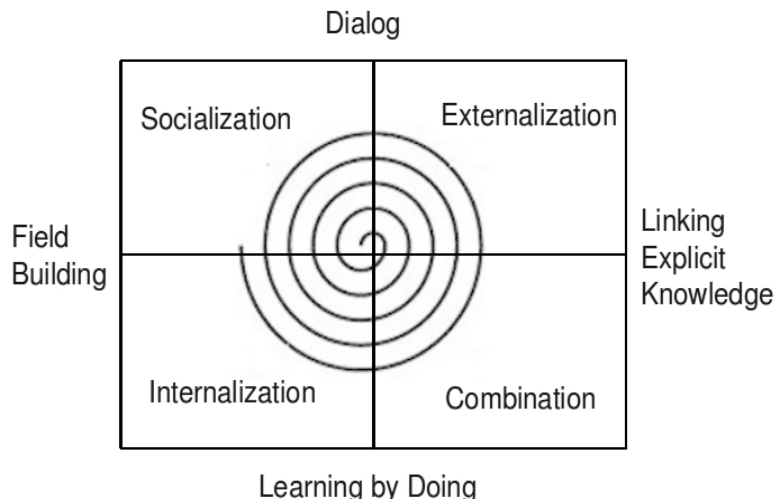

Fig. 1. SECI Model (Nonaka \& Takeuchi, 1995). 
These four types of knowledge conversion: socialization (shared knowledge), externalization (conceptual knowledge), combination (systemic knowledge) and internalization (operational knowledge) in time form a Knowledge Spiral (Figure 1) (Nonaka \& Takeuchi, 1995). Tacit knowledge constitutes the base of organizational knowledge since it is in the minds of the organization's members and can be transmitted to the other members. In this case, these clusters can be modeled through Communities of Practice (CoPs).

\section{Communities}

The term "community" according to Koch and Lacher (2000), is defined as a group of people that share the same interest or are inserted in the same context. Generally speaking, a community can be defined as a group of people that share the same purposes as to permit and/or contribute to a problem's solution. That is, groups of people and/or professionals with similar interests and/or work. Therefore, the basic elements that form any community are the individuals, the way they relate and the context or domain in which these individuals are inserted.

A community can be seen as the identity of a group of people. There are several examples of communities such as all the students in a university program, the people that live in a neighborhood or the persons interested in a given subject such as football or films. These groups may gather to exchange knowledge, that may be collected and stored for future reference and retrieval, helping people that are looking for help in different situations.

\subsection{Overview of Communities of Practice}

There are several types of communities with different characteristics. One of these are the Communities of Practice (CoPs). The term "Community of Practice" was first used in the beginning of the 90 's by Jean Lave and Etienne Wenger to designate the learning that occurred through working practice, even though, in fact, these type of communities already existed, as when company workers learned in their working environment.

Lave and Wenger, in 1991, proposed a knowledge acquisition model as a social process where persons could participate in the common learning at different levels, according to authority and antiquity in the group. Thus a member would start with a peripheral participation, acquiring for example, the community's domain knowledge, moving on to an insertion in the knowledge acquisition context associated to specific community working practices that would became more complex as learning progresses, elevating the member's level of authority.

The key factor that distinguishes CoPs from other types of communities are its objectives, emphasizing knowledge sharing within the group of practitioners through activities such as brainstorming and exchange of reading materials such as articles, news, and experiences. Thus, what links members of a $\mathrm{CoP}$ are the interest relations they have in common.

These groups are organized so professionals from given domains may exchange relevant information about their day-to-day, i.e., their best practices and the way they structure their processes, in addition to sharing solutions to their most common problems. CoPs can be seen as environments that existed in the past, where young apprentices learned from their masters, and when they become masters passed on their acquired knowledge to new 
apprentices. In this environment there is an exchange of knowledge, and in some cases, apprentices may also pass knowledge to their masters.

A key characteristic of CoPs is that each community must center on a given knowledge domain (context), and each member must have a minimum level of domain knowledge to be able to participate in the community. A shared context is essential to the development of a community as it gives sense and direction to the discussions that occur and may help members decide the direction the community will take. The context may include purpose, content, history, and values and make explicit the shared domain knowledge, being decisive for the success or failure of a CoP.

Another important aspect of a $\mathrm{CoP}$ is the community itself, i.e., the way members are kept engaged in joint activities, discussions, mutual help and information sharing.

Interaction is another key requirement for members to belong to this type of community. The functioning of CoPs starts in the way people become members. Persons belong to a CoP when they start to share their best practices. They are linked to each other through the mutual involvement in common activities. This is the coupling that links CoP members as a social entity (Wenger et. al., 2002).

The production of practices by the CoP members is also very important for its definition. It is concentrated in the shared repositories that represent the material traits of the community. Examples of products include: written archives, proceedings, experiences, documents, policies, rituals, specific idioms, blogs, wikis, forums and chats.

Furthermore, the community members must have the same set of goals and purposes. Such purpose set is centered on knowledge sharing between practitioner groups and, for this reason, efficient CoPs are structured mainly around activities of knowledge sharing (for example: video conferences, forums, reading and writing material, meetings, brainstorming, relations and exchange of reading material). A well consolidated community develops its own language and offers its members better communication.

In the literature there are several CoP classifications. Vestal (2003) suggests there are four types of communities:

- Innovation communities: to elaborate new solutions using the existing knowledge;

- Help communities: to solve problems;

- Best Practice communities: searching, validating and disseminating information;

- Knowledge-Stewarding: connecting people, collecting and organizing information and knowledge in organizations.

Each one of these types of CoPs will demand different efforts, levels of functionality and support. Another classification is given by Archer (2006) that identifies four classifications for CoPs:

- Internal Communities of Practice: Communities internal to an organization. They add value to the organization in several ways such as: help conduct strategies, start of new business lines, rapid solution of problems, transference of best practices, development of professional abilities and recruiting and retention of company talents.

- Communities of Practice in Network Organizations: a network organization is a relation between independent organizations. These networks have grown rapidly in number and extension in the last years, and most enterprises belong to at least one network. A supply chain, for example, is a network organization. Organization members in a network work in strait and continuous cooperation in projects and 
processes that involve partnership, common products and/or services. Reasons to build these networks include rapid market insertion, capacity to concentrate in essential competencies, increase of competency due to the network partners, as well as the need to guarantee the availability of resources and materials.

- Formal Networks of Practice: are formal networks that include organizations but are not part of other formal relations. They have a composition that is controlled by taxes and/or acceptance by some central authority that also helps in the organization, facilitating and supporting the members in their communication, events and discussions.

- Self-Organizing Networks of Practice: are networks of individuals with ad-hoc relations and without formal ties. It is an informal network, loosely organized, that has no central administration authority or responsible person, where joining is voluntary and there is almost no explicit compromise. The members may choose to join or leave the community when they want. Most of these networks are virtual, thus the communication strategy is based essentially on knowledge codification.

\subsection{Virtual Communities of Practice (VCoP)}

The Internet, as an agile, flexible and low cost communication mean, was the propulsion factor for the adoption, in large scale, of virtual communities. VCoP can be seen as an environment where people with common interests exchange information through an on-line network, such as the Internet. Through these information exchanges, the participants develop links with other community members and with the community as a whole. Furthermore, the members tend to be physically distant, geographically in different locations.

VCoPs are organized using e-mail, chats, forums, wikis and website technologies for communication, and offer an environment where professionals from given domains can exchange relevant information about their best practices (such as experiences, history, tools, etc.) and the way they structure their processes, as well as share solutions for their most common problems.

An important VCoP characteristic is asynchronous communication, i.e., it is not limited to having all parts interacting at the same time. With this, using the Internet, a disperse group of people can talk asynchronously according to their convenience, during a long period of time, facilitating exchanges that simply could not happen physically. This tends to augment the communication intensity between its members and provide for their basic needs.

Another important VCoP aspect is scalability since the number of members in a virtual community tends to be bigger than in other types of communities, with members being able to enter and leave the community in a more rapid and intense fashion. However, for any $\mathrm{VCoP}$ to have success it must be able to increase the number of participants without loosing the "sense of community", i.e., all the individuals in the community must continue to have the same objectives.

A problem found in $\mathrm{VCoP}$ is establishing a confidence relation between members. As the members will possibly never meet in person, it may be hard to trust entirely another member's practice. Thus, an important aspect in VCoP are the security issues related to its members and practices. VCoPs must implement safety measures to allow entrance of new members and their practice sharing within the community. 
Cothrel and William (2000) have studied Virtual Communities to determine the best way to establish and/or maintain them. They have developed a model that identifies the main activities that must be available to obtain success in the creation of a virtual community. They are:

- Member Development: is the need to promote the growth of the community and substitute the members that leave. It is necessary to clearly define the objectives and member demography as to promote the community.

- Content Management: is related to information content, alliances and infrastructure. Content management must create the members' profile, divide them in sub-communities according to specific topics, capture, disseminate knowledge and create processes that facilitate member involvement.

- Relations Management: must be developed based on explicit general rules that help members solve conflicts that often arise, on their own or with the help of moderators.

According to Kimble and Hildreth (2006), in their work related to CoPs, Wenger identified two fundamental processes that form a duality: participation and reification. Participation is "a social experience of living in the world in terms of joining (adhering) social communities and of active participation in the organizations' social life. Reification is the "process of giving form to our experience, producing objects that solidify that experience". Still according to Wenger, participation and reification are analytically separable, but in fact inseparable. Participation is the process through which people become active participants in the community's practice and reification gives concrete form to the community's experience to produce artifacts.

In VCoPs the participation process is harder to be sustained as the members are dispersed and are not obliged to participate. Reification, at this point, has a more important role in VCoPs. Reification maintains a VCoP feasible. It is therefore necessary a reification process that allows members to formalize their experiences so they can be transmitted to others.

\section{Semantics in the Representation and Retrieval of Knowledge}

Once knowledge becomes the organization's main strategic asset, their success depends on their ability to gather, produce, maintain and disseminate knowledge. The development of procedures and routines to optimize creation, retrieval and sharing of knowledge and information is crucial. This implies in creating knowledge management procedures that are machine processable, since there are enormous amounts of information scattered throughout an organization.

One of the main difficulties in knowledge management is information representation, as a given information may have several different semantic relations at the same time, such as, for example, the homonym semantic relation, the synonym relation and the subclass relation. Thus, to treat knowledge one must have in hands the information obtained from data.

According to Geisler (2008), the relation between data, information and knowledge can be summarized as follows: for data to be considered information it is necessary some type of analysis, a consensus of adopted terms as to their meaning is expected, and to have knowledge, it is necessary to be in synthony with the target public so it can execute an information related action. 
Thus, knowledge comes from the interpretation of data within a context, i.e., from information. Librelotto et. al. (2005) define interpretation as the mapping between a set of structured data and a model of some set of objects in a domain with respect to the desired meaning for these objects and the relations between them. Thus interpretation can be seen as a mapping between notations. For example, the sequence of binary codes (for pictures) or characters in an alphabet (for texts) and what these notations pretend to signify in a given domain.

It can be said that notations are symbols without meaning unless they are given an interpretation. For notations to have meaning they must be mapped to an object in a model. Thus one can conclude that to interpret is to apply the desired semantics to the notation.

The knowledge generation process arises from a process in which given information is compared with many others and combined with people's values and experiences, being these combinations subjected to laws universally accepted. When speaking of knowledge, some hypothesis and delimitations are necessary.

Thus knowledge cannot be described; what is described is information. Also, knowledge does not depend only on personal interpretation, as information, since it requires an experience of the knowledge object. Thus knowledge is in the purely subjective sphere.

In this sense, when humans interpret (understand) something, they symbolically represent the domain objects in some model, as well as the relations between these objects. Humans have the semantics of a domain in their minds, which is well structured and interpreted. However, as humans are not capable of manipulating the complexity of the whole, they need to find models (reduced/partial) to understand and work reality.

When a person reads a poetry book, for example, he reads notations in the pages and interprets them according to his mental model. He interprets giving them semantics. If one wishes to spread knowledge contained in a text, it must be made available to other persons, expecting them to furnish a semantic interpretation using his mental models. Therefore there will be knowledge in that text only if there is interpretation.

The objective of knowledge representation research is that computers may help in the spreading of knowledge. For this to be possible, it is necessary to partially automate the interpretation process, which means that it is necessary to build and represent in a computer usable format some portion of human's mental models.

\subsection{Structuring Knowledge}

To automate the knowledge management process, it is necessary to structure the existing domain knowledge in such a manner that a computer can process and make decisions based on that knowledge. This means passing from the information level to the knowledge level.

Knowledge Representation is something that substitutes the object or real phenomenon as to permit an entity to determine the consequences of an act through thought instead of realization (Davis et al., 1993). Knowledge representation is thus a way of structuring and codifying what is known about a domain.

There are several ways of organizing knowledge that can be differentiated between the logic adequacy, that observes if the formalism being used is capable of expressing the knowledge that one wishes to represent, and the notation convenience, that verifies the representation language conventions. The ways of structuring knowledge can be divided in (Librelotto et. al., 2005):

- Universal type for internal representation of information: 


\section{- Feature Structures.}

- Systems based on lists of terms: normally this type of list has a simple structure for knowledge representation. Their main representatives are:

- Dictionaries;

- Indexes.

- Systems based on graphs: determine associations between the terms through a set of semantic relations. The best known examples are:

- Taxonomies;

- Thesaurus;

- Ontology.

Feature Structures, when used to describe information, puts them in compartments that associate the name of an attribute to a value. This value may be an atomic value or another feature structure.

A dictionary is a set of language vocabulary or terms proper to a science or art, usually organized in alphabetical order with their respective meaning, or its version in another language. May also be seen as a mapping of terms to its description or definition. The main characteristics of a dictionary, according to (Librelotto et. al., 2005), are:

- Is a simple document for the definition of terms that require clearing, with the objective of enhancing communication and reducing the risk of ambiguity;

- Is continually evaluated and, as new terms are found, the dictionary evolves with the addition of these new terms;

- Is made in parallel to the requirements specification.

An index is a detailed list of terms, subjects, people's names, geographical names, happenings, etc., usually in alphabetical order, with an indication of its location in the repository or publication in which they are defined or in which they appear.

For example, a remissive index in a book is an index in alphabetical order containing the different subjects treated in the book, with an indication of the page, chapter, etc. in which they appear. Thus, while an index points to all the occurrences of a concept, facilitating retrieval, a dictionary only gives a concept's definition.

Taxonomy is a classification science. It is a classification system that describes the hierarchical relationship between concepts, identifying members in classes and subclasses. According to (Librelotto et. al., 2005), a good taxonomy must present only one dimension, the categories must be mutually exclusive, a concept must be found in one place only, and it must be exhaustive, with all possibilities included.

Thesaurus is an instrument that gathers terms chosen from a conceptual structure previously established, for indexing and retrieval of documents and information in a given domain. If compared to a taxonomy, a thesaurus may be seen as an extension of a taxonomy, more complete for the description of a domain, allowing other types of relations between terms, in addition to a simple hierarchy. For example, given a term, the thesaurus indicates the terms that have the same meaning, its super class, its subclasses, etc.

Thus, a thesaurus is the vocabulary of a controlled indexation language, formally organized, in such a way that the relations between the concepts are made explicit. Situated between an ontology and a taxonomy, the thesaurus describes relations of synonymy and hierarchies.

As for ontologies, there are today different definitions and characterizations. An often referenced definition is that given by Gruber (1995) that states that and ontology is an explicit and formal specification of a shared conceptualization. This means that an ontology 
conceptualizes an abstract model of some world phenomenon into some consensual knowledge, shared by all. Furthermore, the concepts, properties, functions, axioms must be explicitly specified and be computer manipulated. In this sense, an ontology is an extension of a thesaurus.

Ontologies do not always have the same structure, but some characteristics and components may be found in most of them. For Gruber (1995) the basic ontology components are its classes, relations, that represent the interactions between concepts, axioms and instances, that represent data. For Uschold and Jasper (1999), an ontology may have a variety of forms, but necessarily includes a vocabulary of terms and some specification of their meaning. This includes definitions and an indication of how the concepts are inter related, collectively imposing a structure to the domain and restricting the possible interpretations of the terms. Therefore there is a strong connection between the means of expressing knowledge seen above. Ontology, thesaurus, taxonomy, index and dictionary are similar in the following aspects:

- They are approaches to structure, classify, model and represent concepts and relations belonging to a domain;

- Allows a community to adopt and use the same set of terms in a clear and non ambiguous manner;

- The meaning of each term is specified in some way in a certain level of detail.

However, the concepts and their relations are described and defined in different manners among these types of knowledge representation. Furthermore, different aspects of the knowledge structure are implemented in each one of them. Among them, the one considered more adequate for knowledge representation in communities are the ontologies as they offer the following advantages: concept reuse in different domains, domain structuring in an unambiguous manner, sharing and interoperability of knowledge between different domains.

\section{Knowledge Management in VCoPs}

According to Drucker (1994), knowledge combined with new technologies, and with the talent of the workers involved in the processes may boost and add value to products and services. Nonaka and Takeuchi (1995) identified that organization's knowledge assets are better mobilized and shared in spaces or places they call 'ba', where the tacit knowledge held by individuals is converted and amplified by the spiral of knowledge.

In this context, conversation management influences significantly the knowledge creation process (Von krogh, Ichijo and Nonaka, 2000). Conversation is an excellent way of exchanging ideas, experiences, opinions and personal belief, making it a fundamental human activity for augmenting organizational knowledge. As they foster group discussion and induce the sharing of new insights, conversations, if well managed, help in the efficiency of relationships and solicitude among collaborators.

Environments must provide services that offer an efficient support and promote the four modes of knowledge transformation and innovation described in Nonaka and Takeuchi (1995), creating the "ba" atmosphere, allowing the creation of solid relations and efficient collaboration. These spaces may be physical (meeting room) or virtual (computer network). In the environments, tools must allow knowledge to be created at an individual level to be 
then transformed into group knowledge and finally into organizational knowledge. Even though these levels are independent, they are constantly Interacting, leading to Innovation. According to Nonaka and Takeuchi (1995), when organizations innovate, they not only process information outside-in, aiming to solve existing problems and adapting to an environment in transformation. They create new knowledge and information, inside-out, aiming to redefine the problems as well as the solutions, and in this process recreate the environment. In this theory, the key to the creation of knowledge is to mobilize and convert tacit knowledge. In this dynamic model, knowledge creation is anchored in the premise that human knowledge is created and expanded through the social interaction between tacit and explicit knowledge.

Independent of the knowledge creation phase, good relationships eliminate fear and distrust, demolishing personal and organizational barriers. Efficient conversations provide a greater level of creativity; stimulate sharing of tacit knowledge and the creation and justification of concepts; are essential to the development of powerful prototypes and lubricate the flow of knowledge through the different organizational levels (von Krogh, Ichijo and Nonaka, 2000).

VCoPs should represent this "ba" space, vouching for its members, promoting socialization between them, creating trust, through mechanisms that guarantee the quality of information, offering solutions for the access, categorization and sharing of knowledge, offering an environment that facilitates the creation, exchange, retention and reuse of knowledge. These environments introduce a new dimension to relations, allowing members to work as a team, collaboratively, increasing their individual and collective knowledge.

Most VCoPs offer resources that facilitate and promote social interaction and information sharing. Socialization, Externalization, Combination and Internalization are supported by the use of social software and knowledge management technology. Social software commonly used in VCoPs include: Email, Instant Messaging, Chats, Forums, Blogs, Wikis, Video Conferencing, Virtual Worlds, etc. In addition, VCoPs also offer users the option to upload data and media.

All these processes generate different types of information that must be managed by the community. Knowledge made available by VCoP members, explicitly or implicitly (through different communication methods or by the upload of documents), must be formalized, captured and stored in information repositories. To organize and allow retrieval, knowledge management techniques may be used.

In a study undertaken by Choo et al. (2000), a diagram of the main resources found in the internet and how they contribute to the four modes of knowledge transformation (Figure 2) is presented.

Although these environments have been useful in establishing new communities and contributed to their success, the task of knowledge conversion has been left on the hands of the community members. Users are responsible for deciding what information to load into the community, help solving other member's problems, etc. The environment offers the communication means and facilitates knowledge transformation. However, the environment is not capable of participating in the process. 


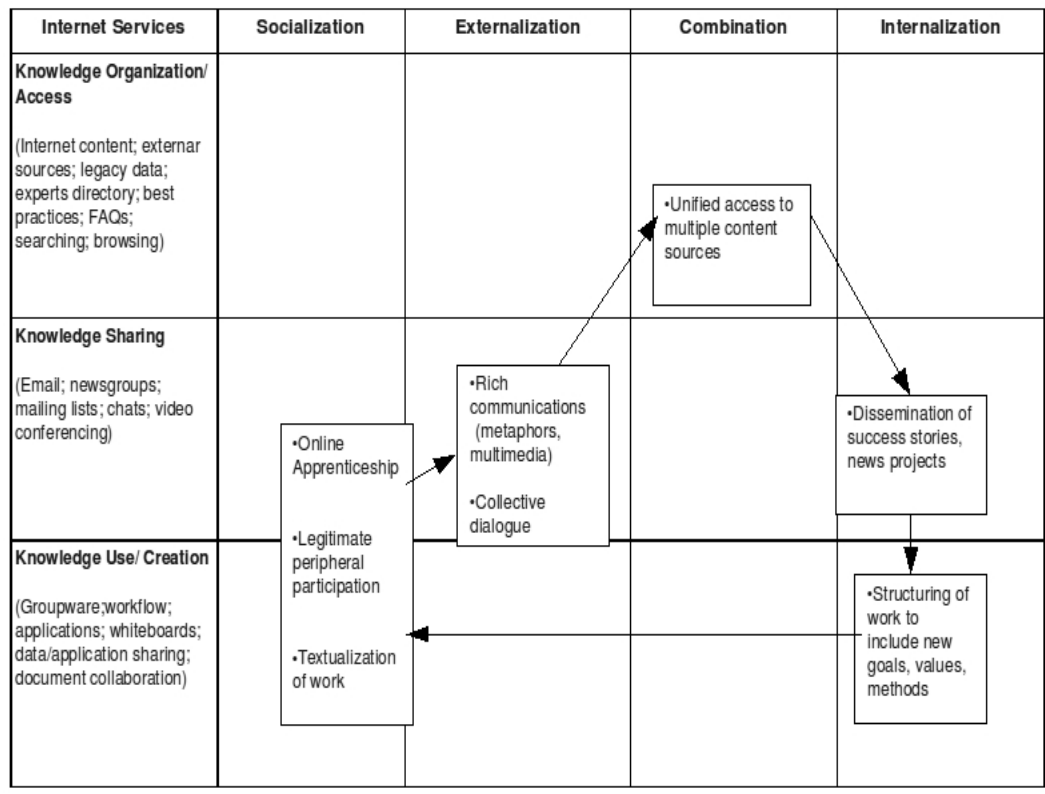

Fig. 2. Intranet Support for Nonaka \& Takeuchi's Knowledge Processes (Choo et al., 2000).

With the introduction of new "intelligent" technology the tendency is that these tasks, that are currently being undertaken by members, be transferred to the environment, that should be capable of interfering in the knowledge transformation process.

This can be achieved by introducing Semantic Web concepts into VCoPs. The Semantic Web project aims the performance of more complex tasks in the information retrieval process. It proposes the existence of collections of structured information and inference rules that will lead to automatic reasoning. For this, techniques associate semantics to the information stored in the web as to make it "understandable" to the computer that is then capable of processing them. According to Berners-Lee (2001), if the Semantic Web is adequately projected it may promote the evolution of human knowledge as a whole.

The Semantic Web principles are implemented in technology layers and patterns (Figure 3). The Unicode layer handles character formatting. The URI (Uniform Resource Identifier) layer allows semantic binding between identifiable resources in the Semantic Web. The XML layer, with the definition of namespaces and schema establish that Semantic Web definitions may be integrated with other patterns based on XML. The RDF (Resource Description Framework) and RDF Schema layers define metadata structure that ensures structural interoperability and allows machine-understood information resource sharing. The Ontology layer provides additional vocabulary to help understand terms found in the Internet. It supports vocabulary evolution and defines relations between concepts. The Digital Signature layer detects modifications in documents. The Logic layer permits rule definition. The Proof layer executes these rules and evaluates, in conjunction with the Trust layer, the mechanisms that allow applications to trust or not the proofs undertaken. 


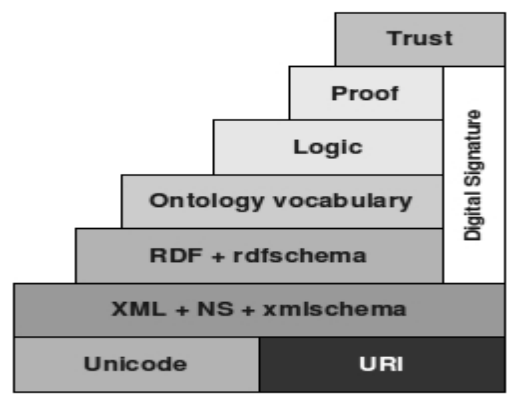

Fig. 3. Semantic Web Layers.

The use of ontology within a community brings several advantages. It helps define the domain of interest of the community, establishing a common vocabulary for better communication between its members, and serves as an indexing structure for the community content, facilitating recovery.

Inference rules can be defined to promote Knowledge extraction. Resources within a community may come in many different formats and types such as images, videos, binary files, as well as text documents that include not only traditional documents as books and papers, but also email messages, forum discussions, wikis, etc.

Text information resources may be classified in two groups. The first includes reports, papers, manual, books, etc. A common characteristic to all these elements is that their authors have made explicit the knowledge they wish to share with the community. Knowledge may be extracted from them "manually", simply by reading. If an analysis of a great volume of documents is necessary to obtain the knowledge for a given activity, the knowledge extraction process may be automated, or semi-automated, using text mining techniques (Feldman \& Sanger, 2006). By integrating knowledge extraction and inference techniques available in the Logic, Proof and Trust layer of the Semantic Web, it is possible to transform explicit knowledge into more explicit knowledge contributing to the Combination phase.

A second group of text information includes email messages, forum discussions, annotations in a Wiki page, etc. In this second group the main characteristic is that the community members do not purposefully explicit their knowledge. They appear in the form of answers to questions, tips to solve a problem, metaphors, analogies, concepts, hypothesis and models. These exchanges between members help them to articulate tacit knowledge that would otherwise be difficult to transmit. It is important for the environment to be able to treat this information, contributing to the Externalization process. Once more, the use of Semantic Web concepts may facilitate the process, helping to transform tacit knowledge into explicit knowledge.

As an example of what can be done, suppose a forum for the discussion of hardware installation. If a member has problems installing any hardware, he may post a message explaining his problem, and other members may give him solution ideas. He may test these ideas and give feedback to the forum, saying what worked and what didn't. If the problem is not solved, other iterations occur. The process continues until the user is satisfied. Eventually there may be problems that continue unsolved even after a long discussion. 
A big challenge is to capture the implicit knowledge contained in these communication processes. The procedure to solve the original problem may be inferred from the sequence of messages exchanged in that specific topic of the forum. If this is possible, the problem and its solution may be stored in the community's knowledge base, making it accessible. If other members have the same or similar problems, they will be able to use this knowledge without having to post a new message to the forum and pass through the same process as the first user. As in forums, messages sent by email or Wiki annotations may also contain embedded knowledge.

\section{Conclusions}

Using an infinity of tools and the web's ease of communication, VCoPs gain space and are today an important domain of research and application, allowing the development of more complete and useful environments for the management of knowledge, i.e., the sharing of their best practices by the community members.

For an effective knowledge transfer between community members it is necessary a high level of confidence between the members and a strong cooperation and collaboration culture. This confidence is developed through work practices that promote and allow members to work together in projects and problems. With this, the members tend to cooperate and collaborate within the community implementing an effective management of the knowledge that circulates through the VCoPs.

VCoPs need computer-based tools that facilitate communication between its members to survive. These tools must provide an efficient management of its information resources. Most environments that support VCoPs offer support for conversation and sharing between group members, as well as repository technology for managing documents. They provide community members with mechanisms to support them when they want to formalize and persist their knowledge and they offer support to the communication processes.

However, these environments only facilitate but do not interfere in the knowledge transformation process. This is done solely be the community members. The adoption of Web Semantic technology in the context of VCoPs presents an interesting option for knowledge management in these communities. The possibility of automatically "reasoning" about the information contained in the repositories may contribute to the knowledge transformation process. In this case, the environment will no longer be only a support tool, but an active member of the community.

Its main contribution would be in the Externalization phase of Knowledge transformation, sometimes considered the key to knowledge creation as it creates new and explicit knowledge from tacit knowledge contained in people's minds. Furthermore, with the use of Semantic Web technologies, VCoP management tends to be easier, since, it is expected it will ameliorate the relations between community members as these members, due to the facility of insertion and knowledge search, tend to make available more of their knowledge, synergistically enriching the community. 


\section{References}

Ahmad, K. \& Al-Sayed R. (2006). Community of Practice and the Special Language "Ground", In: Encyclopedia of communities of practice in information and knowledge management, Elayne Coakes and Steve Clarke, eds., 77-88, Idea Group Reference, ISBN 1591405564, Hershey.

Archer, N. (2006). A Classification Communities of Practice, In: Encyclopedia of communities of practice in information and knowledge management, Elayne Coakes and Steve Clarke, eds., 21-29, Idea Group Reference, ISBN 1591405564, Hershey.

Bolisani, E.; Scarso, E. \& Di Biagi, M. (2006). Economic Issues of Online Professional Communities, In: Encyclopedia of communities of practice in information and knowledge management, Elayne Coakes and Steve Clarke, eds., 148-156, Idea Group Reference, ISBN 1591405564, Hershey.

Berners-Lee, T.; Hendler, J. \& Lassila, O. (2001).The Semantic Web. Scientific American, May, 2001.

Cothrel, J. \& Williams, R. (2000). Four Smart Ways to Run Online Communities. Sloan Management Review, p.81-91, USA.

Choo, C. W; Detlor, B. \& Turnbull, D. (2000) .Web Work: information seeking and knowledge work on the World Wide Web. Boston: Kluwer Academic Publishers.

Davenport, T. \& Prusak, L. (1998). Working Knowledge. Harvard Business School Press. ISBN 1578513014. USA.

Davis, R.; Shrobe, H. \& Szolovits, P. (1993). What is a Knowledge representation?. AI Magazine. p. 17-33.

Drucker, P. (2006). Classic Drucker. Harvard Business. School Press. ISBN 1422101681. USA.

Geisler, E. (2008) Knowledge and Knowledge Systems - Learning from the Wonders of the Mind. IGI Publishing. Illinois Institute of Technology, Hershey, New York, USA.

Goble, C.; Roure, D.; Shadbolt, N. \& Fernandes, A. (2004). Enhancing Services and Applications with Knowledge and Semantics, In: The grid : blueprint for a new computing infrastructure, Foster I. and Kesselman C., eds., 431-458, MorganKaufmann.

Gruber, T. (1995). Toward Principles for the Design of Ontologies Used for Knowledge Sharing. International Journal Human-Computer Studies. p.907-928

Haghirian, P. (2006). International Knowledge Transfer as a Challenge for Communities of Practice, In: Encyclopedia of communities of practice in information and knowledge management, Elayne Coakes and Steve Clarke, eds., 234-238, Idea Group Reference, ISBN 1591405564, Hershey.

Herman, I. (2007). Web Ontology Language (OWL). http://www.w3.org/2004/OWL/, accessed in April 2009.

Haykin, S. (1998). Neural Networks: A Comprehensive Foundations. Prentice Hall. ISBN 0132733501.

Hotho, A.; Nürnberger, A. \& Paab, G. (2005). A Brief Survey of Text Mining. GLDV-Journal for Computational Linguistics and Language Technology, 16-92, May.

Kimble, C. \& Hildreth, P. (2006). The Limits of Communities of Practice, In: Encyclopedia of communities of practice in information and knowledge management, Elayne Coakes and Steve Clarke, eds., 327-334, Idea Group Reference, ISBN 1-59140-556-4, Hershey. 
Koch, M. \& Lacher, M. (2000). Integrating Community services: A Common Infrastructure Proposal. Knowledge-Based Intelligent Engineering Systems and Allied Technologies. Proceedings. Fourth International Conference on. p.56-59. ISBN 0780364007.

Lave, J. \& Wenger, E. (1991). Situated Learning: Legitimate Peripheral Participation. Cambridge University Press: NewYork, NY. USA.

Landini, M. \& Damiani, J. (2001). Knowledge Management: An Exploratory Study in the Brazilian Aerospace Program. Proceedings PICMET'01. ISBN 1890843067. Portland, OR, USA.

Librelotto, G.; Ramalho J. \& Henriques, P. (2005). Representação de Conhecimento na Semantic Web. XXV Congresso da Sociedade Brasileira de Computação: XXIV Jornadas de Atualização em Informática. p. 1210-1261. São Leopoldo, RS. Brasil. (in Portuguese).

Mizzaro, S. (1997). Relevance: The Whole History. Journal of the American Society for Information Science, v.48, n.9, p. 810-832.

Nonaka, I. \& Takeuchi, H. (1995). The Knowledge-Creating Company: How Japanese Companies Create the Dynamics of Innovation. Oxford University Press. ISBN 0195092694. New York.

Russell, S. \&; Norving, P. (2004). Artificial Intelligence. A Modern Approach. Prentice-Hall. ISBN 013080302

Setzer, V. (2006). Data, Information, Knowledge and Competence. Proceedings of the 3rd International Conference on Information Systems and Technology Management. p. 16761695. São Paulo.

Shannon, C. (1948). A Mathematical Theory of Communication. The Bell System Technical Journal, p. 379-423,623-656, 1948.

Uschold, M. (1996). Building Ontologies: Towards a Unified Methodology. In: 16th Annual Conference of the British Computer Society Specialist Group on Expert Systems, Cambridge, UK.

Uschold, M. \& Gruninger. M. (1996). Ontologies: principles, methods and applications. Knowledge Engineering Review, p.93-155.

Uschold, M. \& Jasper, R. (1999). A Framework for Understanding and Classifying Ontology Applications. Proceedings of the IJCAI-99 workshop on Ontologies and Problem-Solving Methods (KRR5). Stockholm, Sweden.

Vestal, W. (2003). Ten Traits for a Successful Community of Practice. Knowledge Management Review, 5(6), 6.

von Krogh, G., Ichijo, K. \& Nonaka, I. (2000) Enabling Knowledge Creation: How to Unlock the Mystery of Tacit Knowledge and Release the Power of Innovation, Oxford University Press.

Wenger, E.; McDermott, R \& Snyder, W. (2002). Cultivating Communities of Practice: A Guide to Managing Knowledge. Harvard Business School Press. ISBN 1578513308. 


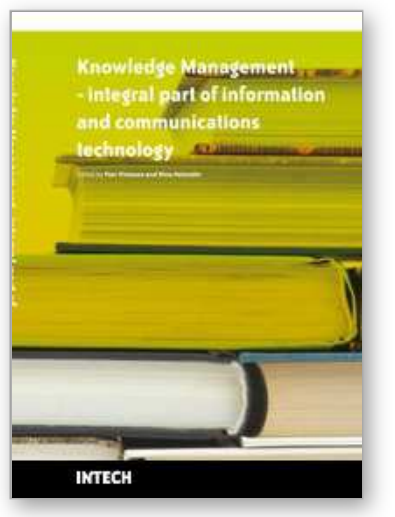

\author{
Knowledge Management \\ Edited by Pasi Virtanen and Nina Helander
}

ISBN 978-953-7619-94-7

Hard cover, 272 pages

Publisher InTech

Published online 01, March, 2010

Published in print edition March, 2010

This book is a compilation of writings handpicked in esteemed scientific conferences that present the variety of ways to approach this multifaceted phenomenon. In this book, knowledge management is seen as an integral part of information and communications technology (ICT). The topic is first approached from the more general perspective, starting with discussing knowledge management's role as a medium towards increasing productivity in organizations. In the starting chapters of the book, the duality between technology and humans is also taken into account. In the following chapters, one may see the essence and multifaceted nature of knowledge management through branch-specific observations and studies. Towards the end of the book the ontological side of knowledge management is illuminated. The book ends with two special applications of knowledge management.

\title{
How to reference
}

In order to correctly reference this scholarly work, feel free to copy and paste the following:

Junio Cesar de Lima, Cedric Luiz de Carvalho and Ana Paula Laboissiere Ambrosio (2010). Knowledge Management in Virtual Communities of Practice, Knowledge Management, Pasi Virtanen and Nina Helander (Ed.), ISBN: 978-953-7619-94-7, InTech, Available from: http://www.intechopen.com/books/knowledgemanagement/knowledge-management-in-virtual-communities-of-practice

\section{INTECH}

open science | open minds

\author{
InTech Europe \\ University Campus STeP Ri \\ Slavka Krautzeka 83/A \\ 51000 Rijeka, Croatia \\ Phone: +385 (51) 770447 \\ Fax: +385 (51) 686166 \\ www.intechopen.com
}

\author{
InTech China \\ Unit 405, Office Block, Hotel Equatorial Shanghai \\ No.65, Yan An Road (West), Shanghai, 200040, China \\ 中国上海市延安西路65号上海国际贵都大饭店办公楼 405 单元 \\ Phone: +86-21-62489820 \\ Fax: +86-21-62489821
}


(C) 2010 The Author(s). Licensee IntechOpen. This chapter is distributed under the terms of the Creative Commons Attribution-NonCommercialShareAlike-3.0 License, which permits use, distribution and reproduction for non-commercial purposes, provided the original is properly cited and derivative works building on this content are distributed under the same license. 